\title{
Assessment of the Role of Men in Family Planning Utilization at Edaga-Hamuse Town, Tigray, North Ethiopia
}

\author{
Addis Adera ${ }^{1}$, Tilahun Belete ${ }^{1}$, Asefa Gebru², Alganesh Hagos ${ }^{2}$, Woldegebriel Gebregziabher ${ }^{3}$ \\ ${ }^{1}$ Department of Nursing, Faculty of Health Sciences, Woldia University, Woldia, Ethiopia \\ ${ }^{2}$ Departments of Nursing, College of Health Sciences, Mekelle University, Mekelle, Ethiopia \\ ${ }^{3}$ Department of Nursing, College of health science, Adigrat, Tigray, Ethiopia
}

Email address:

addisaderagebru@gmail.com (G. A. Adera)

\section{To cite this article:}

Addis Adera, Tilahun Belete, Asefa Gebru, Alganesh Hagos, Woldegebriel Gebregziabher. Assessment of the Role of Men in Family Planning Utilization at Edaga-Hamuse Town, Tigray, North Ethiopia. American Journal of Nursing Science. Vol. 4, No. 4, 2015 , pp. $174-181$. doi: $10.11648 /$ j.ajns.20150404.15

\begin{abstract}
Back Ground: Family planning is a key for slowing unsustainable population growth and the resulting negative impacts on the economy, environment, and national and regional development efforts. Men are also recognized to be responsible for the large proportion of ill reproductive health Suffered by their female partners. In addition; male involvement helps not only in accepting a contraceptive but also in its effective use and continuation. But men involvement in family planning at the study setting is rarely known. Objectives: To assess male involvement in Family planning utilization at EdagaHamuse town, Tigray, North Ethiopia. Methods: A Community based analytical cross-sectional study design was conducted, from August 27, 2014 up to September, 15, 2014. Population of married couples in selected households available during the study period was included in the study. The data was collected using pre-tested self-administered questionnaires. The findings of the study was summarized and presented using tables, descriptive measures and statistical diagrams. The data editing and clearance was done on the same software. Finally, the data was taken to SPSS version 16.0 for the final analysis. And P-value was used. Result: More than $99 \%$ of the subjects have heard about modern family planning methods/current contraceptive use. The most commonly mentioned $114(38.8 \%)$ of modern family planning methods was pills and followed by $91(30.9 \%)$ was inject able. The rate of current contraceptive use is significantly higher for those women with between 3-4 births or having between $1-3$ live children $(34.3 \% ; n=101)$ and $(25.5 \% ; n=75)$ respectively. Of the participants $78(26.5 \%)$ were used Pills by need of 3-4 children ever born. The result shows that the more than half of the subjects $(60.7 \%$; $n=176)$ did get married between 21-28 years old. The result shows that the more than half of the subjects $(59 \% ; n=170)$ had experienced in pregnancy terminated with Abortion (By asking Husband's experience of their wife). Conclusion and recommendation: of the subjects had never been involved themselves in FP with their wife and this may be attributed to negative perceptions recorded among them. More research with larger groups is needed to generalize this result. The majority of the subjects had never been involved themselves in FP with their wife and this may be attributed to negative perceptions recorded among them.
\end{abstract}

Keywords: Family Planning, Men Involvement, Contraceptive

\section{Introduction}

Family planning refers to a conscious effort by a couple to limit or space the number of children they have through the use of contraceptive methods. Contraceptive methods are classified as modern or traditional methods, the modern methods include female sterilization, male sterilization, the pill, the Intera Uterine Device(IUD), injectable, implants, male condom, female condom, diaphragm/foam/jelly, while standard days method and lactation amenorrhea method
(LAM), methods such as rhythm (periodic abstinence), withdrawal, and folk methods are grouped as traditional. The methods considered "long-acting" in this context are IUDs and implants; vasectomy and female sterilization are considered "permanent." Pills, injectable, such as DepoProvera are considered "short-acting "because their lengths of action are only from 1 to 3 months $(1,2)$. By far, the world's largest regional percentage increase in population will be in Africa, which expects about 2.3 billion by 2050 depending on the assumption that SSAs total fertility rate (TFR)- the average number of children per woman) will 
decline from 5.1 to approximately 3.0 by this year $(3,4)$. An estimation of 358000 maternal deaths occurred worldwide in 2008 , a $34 \%$ decline from the levels of 1990 , despite this decline, developing countries continued to account for $99 \%$ (355 000) of the deaths. Sub Saharan Africa (SSA) and South Asia accounted for $87 \%(313,000)$ of global maternal deaths and more than 350 million couples worldwide have limited or no access to effective and affordable FP especially to LAFP methods $(5,6)$.In the least developed countries, use of LARCs/PMs accounts for less than one-fifth (19\%) of the contraceptive method mix. It is estimated that if 5,000 oral contraceptive users were to switch to an intrauterine device (IUD) or implant,approximately1,250unintended pregnancies could be averted over a 5 -year period $(7,8)$. Women who are not satisfied with short-acting methods but still wish to avoid pregnancy need alternative family planning choices. In developing countries, 20 percent to 30 percent of women who use oral contraceptives or injectable stop within two years of starting because of side effects or other health concerns. Many of these women could benefit from switching to an long acting family planning (LAPM) (9). A Published study in Kenya indicated that Kenyan men know about family planning and have a high rate of contraceptive use relative to other African countries. This was also reflected by the relatively high rate of contraceptive usage by the Kenyan women, $24 \%$ of women aged $15-45$ use a modern contraception compared to the $8 \%$ in Ethiopia. About $10 \%$ Kenyan married couples are using a method, which requires male participations, such as condom, periodic, abstinence, withdrawal, or vasectomy $(10,11,12)$.Few researches suggests that male involvement can increase uptake and continuation of family planning methods by improving spousal communication through pathways of increased knowledge or decreased male opposition $(3,4)$. for example, Studies conducted in African contexts have found that limited knowledge about family planning is a key determinant of men's negative perception of and lack of engagement in family planning as well as gender norms regarding men's roles some studies suggest also that spousal communication is low even in cases where men approve of family planning(5,6).Furthermore, the support and encouragement for women and men to enter and complete formal education is essential in bringing about a cultural and social change in attitude towards the economic and social value of family planning. Yet, in countries with high fertility rates and unmet need, men have often been regarded as unsupportive of their partner's use of family planning methods (10).Total Fertility Rate of Ethiopia is 5.4 children per women, population growth rate is estimated to be $2.7 \%$ per year and contraceptive prevalence rate is only $15 \%$ while the unmet need for family planning is $34 \%$. Overall awareness of Family Planning methods is high, at $87 \%$. The roles of the male in making family life decisions including the reproductive health life of his wife are not given emphasis (16). One of the reasons for the new interest in male involvement in family planning services are (16): men are more favorable to the general principle of family planning than had been assumed, male support affects both the adoption and the correct use of female contraceptives, the body of knowledge regarding male involvement programs is growing and improving, and family planning agencies are finding that male involvement programs can be cost effective if they are highly focused and offer male contraceptive methods directly or by referral the international consensus reached at International Conference on Population (3) . Ethiopia is the second most populous country in Sub-Saharan Africa. Total Fertility Rate of Ethiopia is 5.4 children per women, population growth rate is estimated to be $2.7 \%$ per year and contraceptive prevalence rate is only $15 \%$ while the unmet need for family planning is $34 \%$. Overall awareness of Family Planning methods is high, at $87 \%$. The prevalence of long acting and permanent contraceptive methods (LAPMs) in Tigray region was very low which accounts for $0.1 \%$ for implants and no users for intra-uterine contraceptive device (IUCD) and female sterilization. Moreover almost all modern contraceptive use in Ethiopia is dependent on short acting contraceptive methods. Therefore, this study assessed factors affecting utilization of LAPMs in the community can solves the problems and fulfill the needs and right of individual, community as well as the region and provides information for the future plan of the region regarding to LAPMs (14) . Even though there is a family planning practice in Ethiopia, The family planning services will be primarily restricted to maternal and child health Centers where only women will be invited for the service. This result a fast growing population number in Ethiopia, so performing the study has the following significances. It may help to know husbands and wife factors influencing couples contraception use in Edaga Hamus town, It may be help full to increase males involvement in family planning practice and The research may provide a solution to the socio-cultural factors affecting men's practice in men Involvement family planning. The purpose of this study was to assess male involvement in FP utilization at Daga Hamus town.

\section{Methods and Materials}

A Community based cross-sectional study design was conducted from August 27, 2014 up to September 15, 2014 in Daga Hamus town, Tigray, North Ethiopia. Daga Hamus (Tigrigna "Thursday Market") is town in Norther Ethiopia. It Locates 97 Kilometers north of Mekelle in the Misraqawi Zone of the Tigray Religion (or Kill) of Ethiopia. This town has latitude and longitude of $14^{\circ} 11^{\prime} \mathrm{N} 39^{\circ} 34^{\prime} \mathrm{E}$ with an elevation of 2670 meters above sea level. Idaga Hamus is located on "national road 1', in between Freweyni and Adigrat. A number of rock-hewn churches have been reported near this town which includes: Debre Zakarios Giyorgis and Cherqos, a collapsed one at Dengelat, Guwahigot Yesus and Yohannes. Based on figures from the central statistical Agency in 2005, Edaga-Hamus has an estimated total population in the town is 9743.There are one high school, 2 elementary school, one health center, 3 private clinics and 4 private pharmacies. This study was performed 
in each Zone in Edaga Hamus.

The required sample size calculated using the formula

$$
\mathrm{n}=\mathrm{z} 2 \mathrm{pq} / \mathrm{d} 2
$$

- where $n=$ sample size; $z=$ the standard normal deviation which corresponds to the $95 \%$ confidence level (1.96); $p$ =estimate of key proportion You can use $22.2 \%(0.22)$ proportion since it is the contraceptive use rate at Tigray region (EDHS 2011)

- $\mathrm{n}=\frac{1.96^{2} \times(0.22 \times 0.78)}{0.05^{2}}=263.7 \sim 264$

$+10 \%$ contingency, the final $\mathrm{n}$ will be;

$$
264+26=290
$$

All married couples in selected households from the total number of married couples about 290 were selected. The method used was systematic probability sampling techniques regarding the sampling technique; study group from the source of population was choices for each Ketena by systematic sampling (Lottery) method (Ketena1-4). After complete selection of stratified taken over, households was leveled depending on the number of participant by allocated. The first household was selected using table of random numbers, while subsequent households will picked-up by adding the sampling interval using systematic random selection (every $5^{\text {th }}$ )households based on the structured developed questionnaire,290 respondents was interviewed home to home in the community for all selected households that exists based on the sampling frame

A self-administrated questionnaire developed from previous literatures was developed in English and translated into Tigrigna language. Then retranslation of the Tigrigna version into English was done by another professional and checked for consistency with the original version. The investigator. The Tigrigna version was used for collecting information. The questionnaires used for collecting information from the couple was similar expected the one additional question on the male partner questionnaire related to type of marriage.

Data was collected on the variables from couples over 5 days. A Pre-test was carried out using the prepared format in a community that was not being selected for the study. During the field practice, each data collector was made to fill two questionnaires with supervisor close to them. The role and communication of supervisor (the investigator) to data collectors and coordinators was been thoroughly explained.

The findings of the study was summarized and presented using tables, descriptive measures and statistical diagrams. Simple frequencies to see the overall distribution of the study subject with the variable under study was done .Findings were presented by text, and tables. Then, discussion, conclusion and recommendation was prepared. Binary logistic regression was used to assess the independent effect of the predictors on the utilization of family planning and men involvement practice. Statistical inferences were made by using chi-square test and the measure of association was the odds ratio. All covariates with nearly $\mathrm{p} \leq 0.05$ in the bi- variable analysis or potential confounders was included in to the final model to obtain adjusted odds ratio and their $95 \%$ confidence intervals. All statistical tests will be two sided and was considered significant at $\mathrm{P}=0.05$ or less.

Questionnaire was first prepared in English language by the investigator and late was translated to Tigrigna and translated back to English. Training to the data collectors on how to collect the data was provided for 04days. Each data collector was made to fill two questionnaires with supervisor close to them. Discussion was taken place the following day concerning the filled questionnaires. More clarification was given to data collectors on the items they were not being understood during their field practice. The data editing and clearance was done on the same software. Finally, the data was taken to SPSS version 16.0 for the final analysis. Extreme observations and missing values was assessed and managed. Before the data collection ethical approval and clearance was obtained from Mekelle University, College of Health Science and Tigray regional Health bureau. Then it was authenticated by the Adigrat town health office. A formal cooperation letter written from Mekelle University, Tigray regional health bureau and Adigrat town health office was submitted to all concerned bodies in the study area. Kebele administrators was informed and communicated about the purpose of the study, importance and duration of the study in order to get their free and prior informed consent to the survey.

\section{Results}

All the selected 290 married men participants responded to the questionnaire, forming a response rate of $100 \%$. The mean age of the study participants was 30.45 (SD.+10.06) years and $54.8 \%$ were in the age group 25-29 years. More than half of the participants $152(52.8 \%)$ of the respondents had at least able to read and write, the higher education level $83(28.6 \%)$, and $54(18.6 \%)$ had not any reading and writing experience. More than 8 in $10248(85.5 \%)$ of the respondents were orthodox Christian religions followers. Almost all $(100 \%)$ of the respondents were currently married. of the participants $110(37.9 \%)$ were merchant by occupation and followed by Governmental employee $72(24.8 \%)$.Concerning educational status of the men, more than half 236(84.45) had received formal education(Table1).

Table 1. Socio demographic characteristics of the couples from kebelle01, Edaga-Hamus Town, Tigray, Ethiopia, 2014.

\begin{tabular}{llll}
\hline \multirow{2}{*}{ variable } & $\begin{array}{l}\text { Back ground } \\
\text { characteristics }\end{array}$ & Response & \\
\cline { 3 - 4 } & $15-19$ & 38 & Percentage (\%) \\
\hline \multirow{3}{*}{ Age } & $20-24$ & 93 & 13.1 \\
& $25-29$ & 159 & 32.1 \\
& Total & 290 & 54.8 \\
& Orthodox & 248 & 100 \\
Religion & Protestant & 3 & 85.5 \\
& Muslim & 39 & 1 \\
Education & Total & 290 & 13.4 \\
Status & Unable to read and & 54 & 100 \\
\hline
\end{tabular}




\begin{tabular}{llll}
\hline \multirow{2}{*}{ variable } & $\begin{array}{l}\text { Back ground } \\
\text { characteristics }\end{array}$ & Response & \\
\cline { 2 - 4 } & Able to read and write & 153 & 52.8 \\
& Higher education & 83 & 28.6 \\
& level & 290 & 100 \\
& Total & 110 & 37.9 \\
& Merchant & 72 & 24.8 \\
\multirow{5}{*}{ Occupation } & Governmental & 108 & 37.2 \\
& Employee & 290 & 100 \\
\hline & Other & &
\end{tabular}

It was found that the participants More than $99 \%$ of the subjects have heard about modern family planning methods/current contraceptive use. The most commonly mentioned $114(38.8 \%)$ of modern family planning methods was pills and followed by $91(30.9 \%)$ was inject able. of the participants $137(45.58 \%)$ had information about family planning and their partners knowledge on Family planning. However, morethan half of the participants $153(52.02 \%)$ had not information on family planning and their partners awareness on family planning. There was no any statically significance relationship between age and current contraceptive use $(\mathrm{P}=0.35 ; \mathrm{df}=6 ; \mathrm{Chi}-\mathrm{x} 2=0.008)$. However, there was a relationship between educational back ground and current contraceptive use $(\mathrm{P}=0.01 ; \mathrm{Df}=9$; Chi- $\mathrm{x} 2=0.02)$. Both information on FP and their partners information on FP are significant relationship with current contraceptive user $(\mathrm{P}=0.000, \mathrm{Df}=9$, Chi- $\mathrm{x} 2=0.000)$ (Table.2).

Table 2. Women age, education and family size versus their current contraceptive use couples of Edaga Hamus Town, Tigray, Ethiopia, 2014.

\begin{tabular}{|c|c|c|c|c|c|c|c|}
\hline \multirow{2}{*}{ Variable } & \multirow{2}{*}{ Background characteristics } & \multicolumn{6}{|c|}{ Contraceptive current use by women } \\
\hline & & Yes & $\%$ & No & $\%$ & Total & $\%$ \\
\hline \multirow{4}{*}{ Age } & $15-19$ & 22 & 7.48 & 16 & 5.4 & 38 & 12.92 \\
\hline & $20-24$ & 44 & 14.96 & 49 & 16.7 & 93 & 31.62 \\
\hline & $25-29$ & 71 & 24.14 & 88 & 29.92 & 159 & 54.06 \\
\hline & Total & 137 & 45.58 & 153 & 52.92 & 290 & 100 \\
\hline \multirow{3}{*}{ Education } & Unable to read and write & 16 & 5.4 & 38 & 12.92 & 54 & 18.36 \\
\hline & Able to read and write & 73 & 24.82 & 80 & 27.20 & 153 & 52.02 \\
\hline & Total & 137 & 45.58 & 153 & 52.02 & 290 & 100 \\
\hline
\end{tabular}

Husbands' age between 25-29 years was associated with the highest rate of current contraceptive use. In addition those husbands with educational level of able to read and write were associated with high rate of current contraceptive use
$73(24.82 \%)$.Husbands' who have information of FP methods show lower of current contraceptive use $137(45.58 \%)$ (show table 3).

Table 3. Husbands' age, education and their status regarding family planning information versus current contraceptive use by wives, couples, Edaga-Hamus Town, Tigray, Ethiopia, Sep, 2014.

\begin{tabular}{|c|c|c|c|c|c|c|c|}
\hline \multirow{2}{*}{ Variable } & \multirow{2}{*}{ Background characteristics } & \multicolumn{6}{|c|}{ Contraceptive current use by women } \\
\hline & & Yes & $\%$ & No & $\%$ & Total & $\%$ \\
\hline \multirow{4}{*}{ Age } & $15-19$ & 22 & 7.48 & 16 & 5.4 & 38 & 12.92 \\
\hline & $20-24$ & 24 & 8.16 & 49 & 16.7 & 93 & 31.62 \\
\hline & $25-29$ & 71 & 24.14 & 88 & 29.92 & 159 & 54.06 \\
\hline & Total & 137 & 45.58 & 159 & 54.06 & 290 & 100 \\
\hline \multirow{4}{*}{ Education } & Unable to read and write & 16 & 5.4 & 38 & 12.92 & 54 & 18.36 \\
\hline & Able to read and write & 73 & 24.82 & 80 & 27.20 & 153 & 52.02 \\
\hline & Higher education & 48 & 16.32 & 35 & 11.9 & 83 & 28.22 \\
\hline & Total & 137 & 45.58 & 153 & 52.02 & 290 & 100 \\
\hline \multicolumn{2}{|c|}{ Had information on family planning } & 137 & 45.58 & 153 & 52.02 & 290 & 100 \\
\hline \multicolumn{2}{|c|}{ Had informed partners on Family planning } & 137 & 45.58 & 153 & 52.02 & 290 & 100 \\
\hline
\end{tabular}

The rate of current contraceptive use is significantly higher for those women with between 3-4 births or having between 1-3 live children $(34.3 \% ; n=101)$ and $(25.5 \% ; n=75)$ respectively. However, when number of children ever born and alive for a women is adjusted for the ideal interval wanted by women and men for child spacing, none of them remained as significant predictor of current contraceptive use.Inaddition,one third of the total participants, 73(24.8\%) were wanted child spacing between 1-3.(Table.4).

Table 4. Children ever born and alive and ideal interval wanted versus contraceptive current use, in Edaga-Hamus Town, Tigray, Ethiopia, 2014.

\begin{tabular}{|c|c|c|c|c|c|c|c|}
\hline \multirow{2}{*}{ Variable } & \multirow{2}{*}{$\begin{array}{l}\text { Background } \\
\text { characteristics }\end{array}$} & \multicolumn{6}{|c|}{ Contraceptive current use by women } \\
\hline & & Yes & $\%$ & No & $\%$ & Total & $\%$ \\
\hline \multirow{5}{*}{ Child ever born } & $1-2$ & 11 & 3.74 & 30 & 10.2 & 41 & 13.94 \\
\hline & $3-4$ & 101 & 34.3 & 111 & 37.74 & 202 & 68.68 \\
\hline & $5-6$ & 19 & 6.46 & 20 & 6.8 & 39 & 13.26 \\
\hline & $7-8$ & 6 & 2.04 & 2 & 0.68 & 8 & 2.72 \\
\hline & Total & 137 & 45.58 & 153 & 52.02 & 290 & 100 \\
\hline Number of children alive & $1-3$ & 75 & 25.5 & 72 & 24.5 & 147 & 49.98 \\
\hline
\end{tabular}




\begin{tabular}{|c|c|c|c|c|c|c|c|}
\hline \multirow{2}{*}{ Variable } & \multirow{2}{*}{$\begin{array}{l}\text { Background } \\
\text { characteristics }\end{array}$} & \multicolumn{6}{|c|}{ Contraceptive current use by women } \\
\hline & & Yes & $\%$ & No & $\%$ & Total & $\%$ \\
\hline \multirow{9}{*}{$\begin{array}{l}\text { Interval wanted for child } \\
\text { spacing }\end{array}$} & $4-6$ & 53 & 18.02 & 40 & 13.6 & 93 & 31.62 \\
\hline & $7-10$ & 16 & 5.44 & 29 & 9.86 & 45 & 15.3 \\
\hline & $\geq 11$ & 2 & 0.68 & 3 & 1.02 & 5 & 1.7 \\
\hline & Total & 146 & 49.64 & 14 & 48.96 & 290 & 100 \\
\hline & $1-3$ & 73 & 24.8 & 70 & 23.8 & 143 & 48.62 \\
\hline & $4-6$ & 52 & 17.7 & 41 & 13.94 & 93 & 31.62 \\
\hline & $7-10$ & 18 & 6.12 & 29 & 9.86 & 47 & 15.98 \\
\hline & $\geq 11$ & 3 & 1.02 & 4 & 1.36 & 7 & 2.38 \\
\hline & Total & 146 & 49.64 & 144 & 49.64 & 290 & 100 \\
\hline
\end{tabular}

This table5.shows that the majority of the participants

$78(26.5 \%)$ were used Pills by need of 3-4 child ever born

Table 5. Children ever born versus Types of contraceptive current use in Edaga-hamus Town, Tigray, Ethiopia, 2014.

\begin{tabular}{llllllll}
\hline Child ever born & Pills & IUCD & Injection & Norplant & Prolonged breast feeding & Others & Total \\
\hline $1-2$ & $18(6.1 \%)$ & $12(4.1 \%)$ & $8(2.7 \%)$ & - & $1(0.34 \%)$ & $2(0.7 \%)$ & $41(13.9 \%)$ \\
$3-4$ & $78(26.5 \%)$ & $31(10.5 \%)$ & $62(21.1 \%)$ & $2(0.7 \%)$ & $2(0.7 \%)$ & $27(7.2 \%)$ & $20(68.7 \%)$ \\
$5-6$ & $16(5.4 \%)$ & $5(1.7 \%)$ & $15(5.1 \%)$ & $1(0.34)$ & - & $2(0.7 \%)$ & $39(13.3 \%)$ \\
$7-8$ & $2(0.7 \%)$ & - & $6(2.04 \%)$ & - & - & - & $8(2.7 \%)$ \\
Total & $114(38.8 \%)$ & $48(16.3 \%)$ & $91(30.9 \%)$ & $3(1.02 \%)$ & $3(1.02 \%)$ & $31(7.54 \%)$ & $290(100 \%)$ \\
\hline
\end{tabular}

The result shows that the more than half of the subjects $(59 \% ; n=170)$ had experienced in pregnancy terminated with Abortion (By asking Husband's experience of their wife).
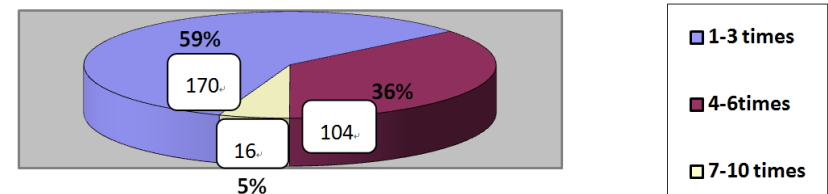

Figure 1. distribution of participant experienced in pregnancy terminated with Abortion (By asking Husband's experience of their wife).

The result shows that the more than half of the subjects $(60.7 \% ; n=176)$ did get married between $21-28$ years old.

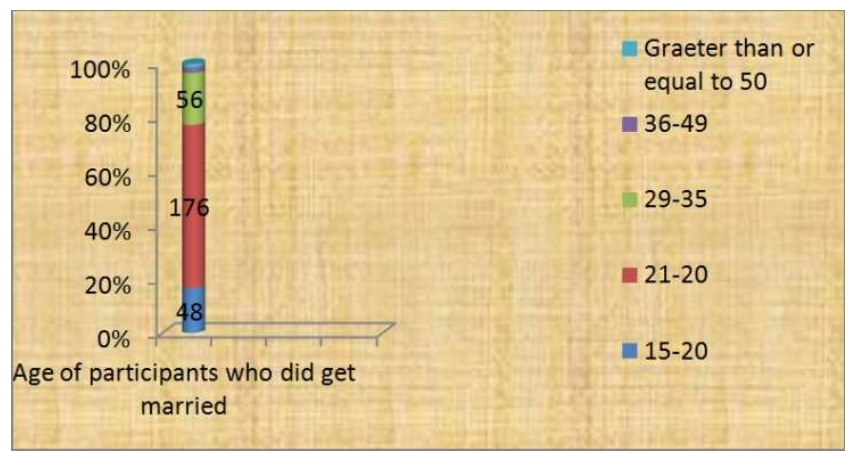

Figure 2. At what age did participants get married.

\section{Discussion}

This community based study used information from men to access factors that were determinant for family planning service utilization by husband's wives and his role in family planning's hypothesized husband's factors affecting family planning use by wife, although wives factors remained to be more predictive variable for their current contraceptive use. Regarding for women who currently use contraceptive method tend to be relatively younger, educated, with large family, and those who perceive their husbands' approval of contraception use. The level of awareness of modern family planning methods by men was quite high in this study. The pattern was similar to that found in the 2008 Nigeria NDHS, in which nine out of every 10 currently married men and women knew of at least one modern family planning method in the south western. Buttressed this point further in their study of family planning in rural Nigeria, which revealed that, generally, knowledge was high for any family planning method(91 percent), while knowledge for any modern family planning method was also high (73 percent); high level of knowledge alone was, however, not sufficient to promote a high level of use. They were with husbands who were younger than 29 years old, have knowledge about family planning, communicate on family planning issues and intitate family planning use. As any cross-sectional study, this study does not show cause and effect relationship with the factors identified as determinant for contraceptive use. Effect of ethnicity could not be investigated as the study was done in area where almost $90 \%$ were Tegaryu. The finding although may not be generalized for the regional or zonal level. It can be used as base line information for target specific intervention and further study by Mekelle University students. The higher contraceptive prevalence would be attributable to the high prevalence of knowledge and positive attitude towards the use and the higher proportion of couples who had discussion on family planning issues and more than 505 of the participants reported discussion about family planning issues and more than $70 \%$ of them both know contraceptive method and approve family planning method utilization. This finding is in contrast with a similar finding in Pakistan (3442). The majority (98.6\%) of the respondents knew that FP is a service for the prevention of pregnancy. The proportion of men who reported current contraceptive knowledge and use was highest in age group 25-29, where $46 \%$ were contraceptive users. The least proportion of current use family planning methods was reported by age group 15- 
19.The possible explanation is that most men strive to have small number of children during their younger age, and at around 29 years. They might want to have their desired number of children. It was found that the participants More than $99 \%$ of the subjects have heard about modern family planning methods/current contraceptive use. The most commonly mentioned of modern family planning methods were pills and followed by inject able types of contraceptive methods. Less than half of the total participants in this study had information about family planning and their partner's knowledge on Family planning. However, more than half of the participants had not information on family planning and their partners' awareness on family planning. This study finding also showed that the husbands with educational level of able to read and write were associated with high rate of current contraceptive use Husbands' who have information of FP methods show lower of current contraceptive use(45\%). Compared with the previous studies conducted by Wondimu and Addisse (2010), the ratio of men discussing family planning with their wives is higher. This discrepancy could be due to time variation, increased awareness of the community about modern contraception, and increased access to family planning services especially through any health setting.

The present study finding showed that the number of children ever born and alive for women is adjusted for the ideal interval wanted by women and men for child spacing, none of them remained as significant predictor of current contraceptive use. Family size of five and above and at least three live children were positively associated with current contraceptive use by women. Family size of women was also found to be significant when adjusted in Multivariate analysis with age and level of education variables (see table 4.)The likelihood of contraceptive usage was predicted by family size. Possible explanations for this could be that those with larger families could have achieved that number of children they wanted to have, which implies that they use methods to limit further child birth. The issue of number of children alive may also be related to child survival. Although the child survival effect was not sought in this study, the effect can be indirectly seen by the number of children alive. Those with larger number of children would use family planning method more than those with lesser number. However the partners' perception of not losing a child (improving child survival) should be a major focus with this regard. The current study result reveled that majority of the participants $78(26.5 \%)$ were used Pills by need of 3-4 child ever born. Among men in Edaga Humus, the condom was the most common family planning method ever used. This study result was in keeping with the findings of Orji and Onwu diegwu 20 and the 2008 Nigeria NDHS, which both showed that the male condom was also the most common modern method ever used by married men. A multivariate analysis of the effect of sociodemo graphic characteristics of the male respondents on their opinions concerning the role of men on decision making with regard to such reproductive health issues as the adoption of family planning, type of family planning method to adopt, and determination of family size revealed that age of the respondents hardly influenced their opinions and perceptions. More significantly, age, education, information on FP of the men tended to influence what they perceived and believed. Specifically, well educated men were more likely to attribute roles for family planning decision making to men, while men in many partners' relationships and age between 25-29 men were less likely to attribute such roles to men. When compared with the previous study which was conducted by Ijadunola et al (2010) found that Eighty-nine percent of men approved of the use of family planning while only about 11 percent disapproved of it. Eighty percent of men had ever used contraception while 56 percent of them were current users. Spousal communication about family planning and other family reproductive goals was quite poor. The sociodemographic correlates of men's opinions included religion, marriage type, educational attainment, and occupation .The probable reason becomes increased from time to time in this study area, and reason for existence of misconceptions may be to message based health education in spite of its frequency it is not deepening to clear the misconceptions of the respondents. Findings from the literature revealed that family planning information and services in Africa are not targeted towards men; services are instead traditionally presented within the context of maternal and child health. A technical report by United Nations Population Fund stated that most reproductive health/family planning service delivery systems are almost entirely oriented to women and provide little or no information about male contraceptive methods. Health workers are sometimes poorly trained in counseling men about safer sexual practices and male methods, and may communicate negative rumors about them.

\section{Conclusion}

This study which conducted the role of men involvement in family planning utilization in Edaga-Hamus town, EdagaHamus, Tigray, Northern Ethiopia. More research with larger groups is needed to generalize this result. The majority of the subjects had never been involved themselves in FP with their wife and this may be attributed to negative perceptions recorded among them. The cultural barrier in itself without any other external influence will demotivate men from getting involved in FP program. The majority of the respondents had never been involved themselves in FP with their wife and this may be attributed to negative perceptions recorded among them. The cultural barrier in itself without any other external influence will demotivate men from getting involved in FP programme. Community sensitization programmes aimed at improving male involvement in FP should be provided by government and nongovernmental agencies. In addition there is need to engage community and opinion leaders so that they can advocate for the use of FP methods in their community. Various studies have shown that providing men with information and involving them in counseling sessions can help them to be more supportive of contraceptive use and more aware of the concept of shared 
decision making.

Men as advocate for contraceptive use, discussion about family planning, perceived approval by husband, women education, are all found to be positive determinants for family planning use by women. Both husband and wife age, child ever born and alive for the couples, are important predictive variables for the wives' use of contraception. Most men have knowledge and favorable attitude towards family planning; some encourage their wives to use family planning method and most of them are in need of family planning methods use in future. The majority of men share decision making on family issues, including family planning with their wives. Unlike the female contraceptive options the men contraceptive options including condom is not widely known by the community. The oral contraceptive pill is giving way for the injectable contraceptive as the leading family planning method preferred and used by majority of women. This finding may warn that if the existing scenario of family planning service is changed from targeting only women to targeting couples, the family planning methods utilization rate may increase. In addition to need for more children, fear of side effects is also becoming an important obstacle for continuation of use of family planning method.

\section{Author Contributions}

$\mathrm{AG}$ and $\mathrm{AH}$ have made substantial contribution to beginning and design ,collection of data,analysis and interpretation of data and in drafting the manuscripts and correcting the comment given by the advisors.

$\mathrm{TB}$ and $\mathrm{AA}$ involved in revising the research paper and the manscript critically for important intellectual context,approval of final version to be published.Also,TB participated in the pproval and funding process,participated in the design of the study participated in its design and coordination. AA and WG also had greater contribution in reviewing the manscript English topography,and helped to draft the manscript.

\section{Acknowledgement}

We are greatful to Mekelle University,college of Health Sciences for their financial support. We would like thank all data collectors and research participants who took part in the study.

\section{References}

[1] EDHS (2005). Preliminary report, CSA and Measure DHS ORC Macro, 2005

[2] EDHS (2011). Preliminary report, CSA and Measure DHS ORC Macro, 2011.

[3] Kabagenyi,A.,Jennings,L.,Reid,A.,Nalwadda,G.,Ntozi,J.,Atuy ambe,L(2014). Barriers to male involvement in contraceptive uptake and reproductive health services: a qualitative study of men and women's perceptions in two rural districts in Uganda.
Reproductive Health, 11:21:1-9http://www.reproductivehealth-journal.com/content/11/1/21

[4] Hartmann M, Gilles K, Shattuck D, Kerner B, Guest G (2012).Changes in couple's communication as a result of a male-involvement family planning intervention. J Health Commun , 17(7): 802-819

[5] Onyango ,MA.,Owoko ,S., Oguttu, M (2010).Factors that influence male involvement in sexual and reproductive health in western Kenya: a qualitative study. Afr J Reprod Health 2010, 14(4 Spec no):32-42.

[6] Nalwadda ,G., Mirembe ,F., Byamugisha ,J., Faxelid ,E(2010).Persistent high fertility in Uganda: young people recount obstacles and enabling factors to use of contraceptives. BMC Public Health 2010, 10:530

[7] Calculation based on methodology described in Hubacher, D., et al. (2007). Contraceptive implants in Kenya: Current status and future prospects. Contraception 75(6):468-473.

[8] JHPIEGO (2010). Systematic Screening Tool; developed by Population Council and adapted for postpartum use by JHPIEGO under the ACCESS-FP project.

[9] Finer, L.B., Jerman, J., Megan L. Kavanaugh, M.L (2012). Changes in use of long-acting contraceptive methods in the $\begin{array}{lll}\text { U.S., } 2007-2009 . & \text { j.fertnstert.98 (4):893-897. }\end{array}$ doi:10.1016/j.fertnstert.2012.06.027.

[10] Beekle AT1, McCabe C(2006).Awareness and determinants of family planning practice in Jimma, Ethiopia. IntNurs Rev. 2006 Dec; 53(4):269-76.

[11] Geography of Africa http://en.wikipedia.org/wiki/category: (Accessed on Dcember1 2012).

[12] Population in Sub-Saharan Africa http://www. wikipediafoundation. org/ (Accessed in December 2012.

[13] Abraham, W., Adamu, A., Deresse, D (2010). The Involvement of Men in Family Planning An Application of Tran theoretical Model in WolaitaSoddo Town South Ethiopia Asian Journal of Medical Sciences 2(2): 44-50

[14] National Population Commision (NPC) Nigeria and ICF Macro (2009) 'Nigeria Demographic and Health Survey 2008' Abuja Nigeria: National Population Commission Abuja and ICF Macro USA.

[15] Duze M.C. and Mohammed I.Z., (2006) 'Male Knowledge, Attitudes, and Family Planning Practices in Northern Nigeria' African Journal of Reproductive Health Vol. 10, No. 3 (Dec., 2006), pp. 53-65 Published by: Women's Health and Action Research Centre (WHARC) [online] Available from: http://www.jstor.org/stable/30032471 [Accessed on 12th April 2011].

[16] National Population Commission (NPC) [Nigeria] and ICFMacro. Nigeria Demographic and Health Survey 2008.Abuja, Nigeria: National Population Commission and ICF Macro, 2009.

[17] YIjadunola,MY., Abiona,TC., Kayode T Ijadunola,KT., Afolabi,OTEsimai,OA., OlaOlorun,FM(2010).Male Involvement in Family Planning Decision Making in IleIfe,Osun State, Nigeria. African Journal of Reproductive Health December 2010; 14(4): 45 
[18] Alemayehu, M., Belachew, T., Tilahun, T (2013). Factors associated with utilization of long acting and permanent contraceptive methods among married women of reproductive age in Mekelle town, Tigray region, North Ethiopia. International Conference on Family Planning.http://www.xcdsystem.com/icfp2013/program/index. $\mathrm{cfm} ? \mathrm{aID}=1191 \&$ seID $=497$

[19] Determinants of family planning http://www.who.int/ (Accessed in 2012).

[20] Dr-Mengstu-Asnake http://www.Impatientoptimists.org/Authors/A/ (Accessed on December 01, 2011).

[21] National Population Commission (NPC) [Nigeria] and ICF Macro, Nigeria Demographic and Health Survey 2008, National Population Commission and ICF Macro, Abuja, Nigeria, 2009.

[22] Okwor,E.,Olaseha,I (2010). "Married men's perception about spousal use of modern contraceptives: a qualitative study in Ibadan northwest local government area, southwest Nigeria," International Quarterly of Community Health Education, 30( 3): 223-238.

[23] Ankomah,A., Oladosu,M., Anyanti,J(2011). "Myths, misinformation and communication about family planning and contraceptive use in Nigeria," Open Access Journal of Contraception, 2:95-105

[24] Shattuck,D., Kerner,B., Gilles,K., Hartmann,M., Ng'ombe,T., Guest,G(2011). "Encouraging contraceptive uptake by motivating men to communicate about family planning: the Malawi Male Motivator project," The American Journal of Public Health, 101(. 6): 1089-1095

[25] Hartmann,M . Gilles,K., Shattuck,D., Kerner,B., Guest,G(2012). "Changes in couples' communication as a result of a male-involvement family planning intervention," Journal of Health Communication, vol. 17, no. 7, pp. 802-819, 2012

[26] Berhane., Biadgilign,S., Amberbir,A., Morankar,S., Berhane,A., Deribe, K(2011). "Men's knowledge and spousal communication about modern family planning methods in Ethiopia," African Journal of Reproductive Health,15( 4):2432.

[27] Kabagenyi,A., Jennings,L., Reid,A.,Nalwadda,G.,Ntozi,J., Atuyambe,L(2011). "Barriers to male involvement in contraceptive uptake and reproductive health services: a qualitative study of men and women's perceptions in two rural districts in Uganda," Reproductive Health,11(21): 201-209.

[28] .Kaba ,M 2007).. Fertility regulations among women in rural communities around Jimma, Western Ethiopia, Ethiop. J.Health Dev,( 14):117-125.

[29] Central Statistical Authority, ORC. MACRO. Ethiopia Demographic and Health Survey (2011). Addis Ababa and Maryland. CSA and ORCMacro. 2010.

[30] Marrida ,H.,Ulla ,L(2004). Women's Empowerment and fertility decline among the Pare of Kilimanjaro region, Northern Tanzania, Social Science and Medicine 58(2004) page 1099-1115.
[31] Gebrekidan, $M(2010)$. The role of men in fertility and family planning programme in Tigray region, Ethiop. J.Health Dev. $16: 247-255$

[32] Yigzaw $K(2010)$.Contraceptive prevalence and factors associated with usage of contraceptives around Gondar Town, Ethiop. J. Health Dev. 2010:14(2): 328-339.

[33] Olayemi, C. O. Aimakhu, F. A. Bello et al(2007). "The influence of social support on the duration of breast-feeding among antenatal patients in Ibadan," Journal of Obstetrics and Gynaecology,27(8):802-805

[34] Hussain,H.,Wahid,I.,Khan,AA.,Reham,ZU.,Iftikhar,B.,Ismail, T(2012).”The role of effective communication between couples about contraceptive use," Journal of Medical Sciences.20(1):19-21

[35] Odu, O.O., Ijadunola, K.T., Komolafe, J.O., Adebimpe, W.t (2006)."Men's Knowledge of and attitude with respect to family planning in a suburban Nigerian Community," Nigerian HJournal of Medicine.15 (3):260-265.

[36] Wondimu, A and Addisse, A (2010).'The involvement of men in Family planning: An application of Trans-Theoretical Model in WolaitaSoddo Town South Ethiopia," Asian Journal Of Medical Sciences.2 (2):44-50.

[37] Lalla $T(2005)$. Male involvement in family planning: a review of the literature and selected program initiatives in Africa. November 1996. Available at: http: //sara.aed.org/ publications/ reproductive health/ family planning/html/male.htm. Accessed Nov 1, 2005.

[38] Yljadunola, M, Abiona, TC., Ijadunola,KT., Olusegun T Afolabi,OT.,Esimai,OA., OlaOlorun,FM (2010). Male Involvement in Family Planning Decision Making in IleIfe, Osun State, Nigeria African Journal of Reproductive Health December 2010; 1

[39] Paul Kisia Malalu, Koskei Alfred, Robert Too, Amon Chirchir. Determinants of Use of Modern Family Planning Methods: A Case of Baringo North District, Kenya. Science Journal of Public Health. Vol. 2, No. 5, 2014, pp. 424-430. doi: 10.11648/j.sjph.20140205.18

[40] Hailay Gebremichael, Fisaha Haile, Awrajaw Dessie, Alula Birhane, Mussie Alemayehu, Henock Yebyo. Acceptance of Long Acting Contraceptive Methods and Associated Factors among Women in Mekelle City, Northern Ethiopia. Science Journal of Public Health. Vol. 2, No. 4, 2014, pp. 349-355. doi: 10.11648/j.sjph.20140204.27

[41] Alemtsehay Mekonnen, Kerebih Asrese. Household Decision Making Status of Women in Dabat District, North West Ethiopia, 2009 Gc. Science Journal of Public Health. Vol. 2, No. 2, 2014, pp. 111-118. doi: 10.11648/j.sjph.20140202.20

[42] Habtamu Mellie Bizuayehu, Direslgne Misker Abyu, Hailu Fekadu Demessie. Assessment of Time of Sexual Initiation and Its Associated Factors among Students in Northwest Ethiopia. Science Journal of Public Health. Vol. 3, No. 1, 2015, pp. 10-18. doi: 10.11648/j.sjph.20150301.13 